\title{
The Liquid Chromatographic Determination of Chlorogenic and Caffeic Acids in Xu Duan (Dipsacus asperoides) Raw Herb
}

\author{
Jarryd L. Pearson, Samiuela Lee, Harsha Suresh, Mitchell Low, Marnilar Nang, \\ Swastika Singh, Franklin Lamin, Magdy Kazzem, Shaun Sullivan, and Cheang S. Khoo
}

Herbal Analysis and Pharmacological Laboratories (HAPL), Centre for Complementary Medicine Research,
University of Western Sydney, P.O. Box 1797, Penrith South DC, NSW 1797, Australia

Correspondence should be addressed to Samiuela Lee; s.lee@uws.edu.au

Received 23 January 2014; Accepted 24 February 2014; Published 4 May 2014

Academic Editors: A. M. Haji Shabani and V. A. Lemos

Copyright (C) 2014 Jarryd L. Pearson et al. This is an open access article distributed under the Creative Commons Attribution License, which permits unrestricted use, distribution, and reproduction in any medium, provided the original work is properly cited.

\begin{abstract}
A validated analytical method is reported for the analysis of chlorogenic and caffeic acids in Xu Duan (Dipsacus asperoides) in the dried raw herb. The ground samples were extracted by ultrasonication in water and the extract was analysed by LC-PDA with identity confirmation by (+)ESI-MS/MS. A C18 column was used with a $0.1 \%$ aqueous formic acid : methanol gradient mobile phase. The analytes were quantified $325 \mathrm{~nm}$. With the MS detector, using the chlorogenic acid precursor ion with $\mathrm{m} / z 354$, ions with $\mathrm{m} / z$ 191 , and 85 were produced. For caffeic acid the precursor ion with $m / z 181$, ions with $m / z 163,135$, and 89 were produced. The amount of chlorogenic and caffeic acids in the raw herb was found to be 4.46 and $0.63 \mathrm{mg} / \mathrm{g}$, respectively, and the method LOD was 0.13 and $0.02 \mathrm{mg} / \mathrm{g}$, respectively.
\end{abstract}

\section{Introduction}

Dipsacus asperoides or commonly known as Xu Duan is a perennial plant distributed in mountainous regions of southwestern China and has been used in Chinese traditional folk medicine for its antibacterial and anti-inflammatory properties [1]. The herb has a bitter, pungent, and a slightly warm flavour. The root has been used extensively for the treatment of liver and kidney dysfunctions. The herb is claimed to tonify the liver and kidneys, strengthen bones and sinews, prevent miscarriage, and help in the regeneration of flesh. Other uses for the herb include the treatment of trauma and fractures of bones and removal of blood stasis, thus relieving pain and swelling $[2,3]$.

There is very little published literature on the HPLC (high performance liquid chromatography) analysis of Xu Duan (Dipsacus asperoides). The majority of published articles on this herb are on their biological activity or effect. The analysis of chlorogenic and caffeic acids in Xu Duan has only been reported in one paper [3]. In that study the powdered herb was extracted with boiling ethanol and the extract analysed using a C18 column with a mobile phase of acetonitrile : water
(20:80) - no wavelength of detection was stated, and no aspects of validation reported.

Chlorogenic and caffeic acids (structure shown in Figure 1) are hydroxycinnamic acids and are related in that chlorogenic acid is the ester of caffeic acid with the 3-hydroxyl group of quinic acid.

Both compounds are known to have antioxidant properties [3-9] and show an ability to inhibit platelet aggregation [2]. Caffeic acid also has antiprostaglandin properties which are a property of conventional drugs used to treat dysmenorrhoea [10]. This ability could explain its frequent inclusion in herbal formulations for the treatment of the gynaecological ailment dysmenorrhoea.

The lack of comprehensively validated HPLC methods for $\mathrm{Xu}$ Duan used in this study reinforced the need to develop and validate methods used for this herb. Analysis of Xu Duan had very little published literature. The validated method developed was used to quantify the analytes of interest in the raw herb sourced from different suppliers. The differences in concentration of the selected analytes in the different sourced herbs may be due to factors like growing conditions, time of harvest, postharvest treatment, storage conditions, and age of 
<smiles>O=C(O)/C=C/c1ccc(O)c(O)c1</smiles>

FIGURE 1: Structure of chlorogenic acid (a) and caffeic acid (b).

herb. This work reports a LC-PDA (liquid chromatographyphotodiode array detection) method for the determination of chlorogenic and caffeic acids in the Xu Duan raw herb, with MS identity confirmation of the analyte.

\section{Experimental}

2.1. Apparatus. LC-PDA experiments were performed on a Varian (Varian Australia, Sydney, Australia) chromatography system equipped with $2 \times$ ProStar 210 solvent delivery modules, a ProStar 430 autosampler, a ProStar 500 column valve module, and a ProStar 335 PDA detector. This system was controlled by the Varian Star MS workstation (version 6.5). A tandem MS/MS detector with a positive electrospray ionisation ((+) ESI-MS/MS) interface was used for analyte identity confirmation. The LC system used was the same as for the LC-PDA method, except that a Varian 1200L triple quadrupole MS/MS detector replaced the PDA and only $20 \%$ of the total flow of $1 \mathrm{~mL} \mathrm{~min}^{-1}$ was diverted to the ESI source.

2.2. Reagents and Materials. The herb sample used for the validation was supplied by the Win-Duc Herb Company (Sydney, NSW, Australia). This herb sample is referred to as R-I. Two other samples were purchased, one from the Chinese Ginsengs Herbal Company and the other from Pine Mountain Herbs, both suppliers are located in the Chinatown area of Sydney (NSW, Australia); these samples are referred to R-II and R-III, respectively. A sample was also supplied from the University of Western Sydney's UniClinic (NSW, Australia), referred to as R-IV. The chlorogenic acid (95.06\%) and caffeic acid (98.30\%) standards were obtained from Sigma-Aldrich (CA, USA).

Methanol, ethanol, and formic acid (AR grade) used were purchased from Biolab (VIC, Australia). Mallinckrodt Baker Inc. supplied the n-hexane and ethyl acetate used for the extraction solvent optimisation. Acetonitrile (LC grade) was from J.T.Baker (NJ, USA). Ultrapure water $(>18.2 \mathrm{M} \Omega / \mathrm{cm})$ was obtained from an Elga (Buckinghamshire, UK) Purelab Prima 7 water purification unit.

2.3. Preparation of Standard Solutions. A mixed stock calibration solution containing an accurately known concentration of approximately $174 \mu \mathrm{g} / \mathrm{mL}$ chlorogenic acid and $66 \mu \mathrm{g} / \mathrm{mL}$ caffeic acid was prepared by making up $1.8358 \mathrm{mg}$ and $0.6705 \mathrm{mg}$ of chlorogenic acid and caffeic acid, respectively, to $10 \mathrm{~mL}$ with methanol. The standards were stored at $-10^{\circ} \mathrm{C}$ and discarded if not used within 2 days as the peak area decreased by $\geq 2 \%$ after this time.

2.4. Preparation of Calibration Dilutions Solutions. A mixed standard containing 8.7, 26.2, 43.6, 87.3, 130.9, and $174.5 \mu \mathrm{g} / \mathrm{mL}$ of chlorogenic acid and 3.3, 9.9, 16.5, 33, 49.4, and $65.9 \mu \mathrm{g} / \mathrm{mL}$ of caffeic acid by diluting $50,150,250,500$, 750 , and $1000 \mu \mathrm{L}$ of the mixed calibration stock standard solution to $1000 \mu \mathrm{L}$ with methanol was prepared.

2.5. Preparation of the Raw Herb for Analysis. Grind the dried Xu Duan $(100 \mathrm{~g})$ samples to pass through a $212 \mu \mathrm{m}$ sieve. Sieve the sample twice to ensure that it is homogenous.

2.6. Extraction Solvent and Method Optimisation. The ground raw herb sample was extracted using six different solvents (with five replicates per solvent) to determine which was most efficient. The solvents used were methanol, water, aqueous methanol $(50: 50 \% \mathrm{v} / \mathrm{v})$, absolute ethanol, ethyl acetate, and hexane. Accurately weighed quantities of the sample (0.950-1.050 g) were transferred into volumetric flasks $(100 \mathrm{~mL}), 95.0 \mathrm{~mL}$ of the solvent added, and the mixture sonicated for $2 \times 30 \mathrm{~min}$, with the sample allowed to cool between sonications. The sample was made to volume with the extraction solvent and passed through a $0.45 \mu \mathrm{m}$ PVDF (polyvinylidene fluoride) syringe filter into a $2 \mathrm{~mL}$ autosampler vial for analysis.

The ground raw herb sample was extracted with the selected optimum solvent (which was found to be water) using three different extraction methods (with five replicates per method). The extraction methods to be used were sonication, reflux, and Soxhlet.

(a) Sonication Extraction. This method is the same as described in the extraction solvent optimisation, except that the optimum solvent (which was found to be water) was used.

(b) Reflux Extraction. The sample was accurately weighed $(0.950-1.050 \mathrm{~g})$ into a round bottom flask $(100 \mathrm{~mL})$ and $90.0 \mathrm{~mL}$ water added before refluxing for $1 \mathrm{~h}$. After cooling the solvent was decanted into a volumetric flask $(100 \mathrm{~mL})$ and made up to volume with water.

(c) Soxhlet Extraction. A known quantity (0.950-1.050 g) of the sample was weighed into a $100 \mathrm{~mL}$ cellulose extraction thimble and placed in a Soxhlet extraction apparatus. $90.0 \mathrm{~mL}$ water was placed in round bottom flask $(100 \mathrm{~mL})$ and the sample extracted for $3 \mathrm{~h}$. After cooling, the solvent was quantitatively transferred to a volumetric flask $(100 \mathrm{~mL})$ and made up to volume for analysis.

2.7. Residual Analyte following Extraction Using the Optimum Extraction Solvent and Method. Using the optimal extraction method and solvent (sonication and water, resp.), 
TABLE 1: Mobile phase composition for the HPLC analysis of Xu Duan.

\begin{tabular}{lcc}
\hline Time $(\mathrm{min})$ & $0.1 \%$ aqueous formic acid & \% methanol \\
\hline 0 & 82 & 18 \\
10 & 72 & 28 \\
15 & 70 & 30 \\
15.5 & 5 & 95 \\
25 & 5 & 95 \\
25.5 & 82 & 18 \\
35 & 82 & 18
\end{tabular}

Note: the flow rate was $1 \mathrm{~mL} / \mathrm{min}$.

the residual herb sample following the extraction described was reextracted three more times. The combined extracts were concentrated to $5.0 \mathrm{~mL}$ and analysed. This result gives an estimate of the extraction efficiency.

2.8. Extraction of the Raw Herb Sample. Approximately $0.5 \mathrm{~g}$ $(0.450-0.550 \mathrm{~g})$ of the raw herb sample was weighed and transferred to a $100 \mathrm{~mL}$ volumetric flask. $95.0 \mathrm{~mL}$ of water was added and the mixture was sonicated for $2 \times 30 \mathrm{~min}$. The sample solution was cooled to room temperature between extractions. After cooling the sample solution was made up to volume, before filtering through a $0.45 \mu \mathrm{m}$ PVDF membrane filter into a $2 \mathrm{~mL}$ autosampler vial for analysis.

2.9. Recovery Studies for the Raw Herb. A mixed spiking solution was prepared by weighing 43.21 and $7.03 \mathrm{mg}$ of chlorogenic and caffeic acids, respectively, into a $25 \mathrm{~mL}$ volumetric flask and was made to volume with methanol. For the $100 \%$ spike level, $250 \mu \mathrm{L}$ of the spiking solution was added to an accurately weighed quantity of the herb sample $(\sim 1.0 \mathrm{~g})$. For the 50 and $200 \%$ spike levels, the spiking volumes were adjusted accordingly. Seven replicates for each spike level were carried out to give a total of twenty-one samples.

2.10. LC-PDA Analysis and ESI-MS/MS Conditions. The gradient mobile phase composition for the LC analysis of chlorogenic and caffeic acids is summarised in Table 1.

Column oven temperature was set to $30^{\circ} \mathrm{C}$ and flow rate to $1.0 \mathrm{~mL} / \mathrm{min}$. With this gradient program the column head pressure varied from 1500 to $2300 \mathrm{psi}$. The injection volume was $6 \mu \mathrm{L}$ with a flush volume of $30 \mu \mathrm{L}$. Quantitation for both analytes was carried out at $325 \mathrm{~nm}$.

ESI-MS/MS was used for identity confirmation. The MS/MS conditions set as follows: nebulisation gas temperature $350^{\circ} \mathrm{C}$, at $19 \mathrm{psi}$; needle voltage $-4100 \mathrm{~V}$ at $15 \mu \mathrm{A}$; shield voltage $-300 \mathrm{~V}$, capillary voltage $-60 \mathrm{~V}$, and MS detector at $-1400 \mathrm{~V}$ for chlorogenic acid; nebulisation gas temperature $400^{\circ} \mathrm{C}$, at $18 \mathrm{psi}$; needle voltage $4200 \mathrm{~V}$ at $11 \mu \mathrm{A}$; shield voltage $300 \mathrm{~V}$, capillary voltage $35 \mathrm{~V}$, and MS detector at $1600 \mathrm{~V}$ for caffeic acid. Argon is used as the collision induced dissociation (CID) gas. The precursor ions for chlorogenic and caffeic acid were monitored at $\mathrm{m} / z 354.0$ and $\mathrm{m} / z$ 181.0, respectively. The precursor ion for chlorogenic acid was subject to CID and

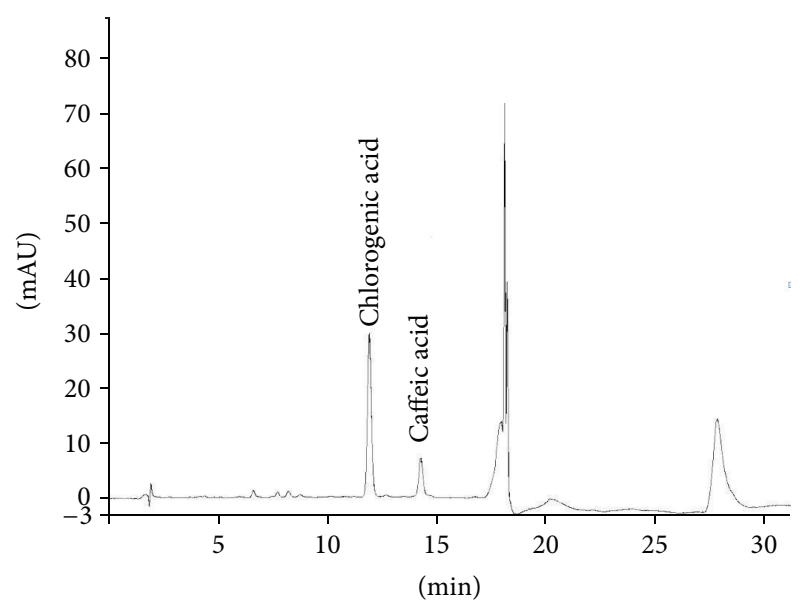

Figure 2: A HPLC-PDA chromatogram for the extract of the Xu Duan raw herb $(\lambda=325 \mathrm{~nm}$, chlorogenic acid at $11.9 \mathrm{~min}$, and caffeic acid at $14.3 \mathrm{~min})$.

the daughter ions with $\mathrm{m} / z 191.0$ and 85.0 were monitored. The precursor ion for caffeic acid was subject to CID and the daughter ions with $m / z 163.0,135.0$, and 89.0 were monitored.

The $m / z$ of the daughter ions for the ESI-MS/MS analysis was selected by direct infusion of the pure standard solutions in methanol into the MS/MS. The daughter ions were chosen based on the area curves of each daughter as shown by the collision cell breakdown display of the operating software. Conditions were selected so as to produce two daughter ions for identity confirmation, which meets the standard set by the European Commission Directorate for Agriculture guidelines [11].

\section{Results and Discussion}

3.1. Chromatograms Obtained. Chromatograms obtained at $325 \mathrm{~nm}$ for chlorogenic acid and caffeic acid gave the best compromise between sensitivity and baseline noise. Figure 2 shows a representative HPLC-PDA chromatogram for a sample of Xu Duan raw herb extract.

3.2. Extraction Solvent and Method Optimisation. The results for the extraction solvent optimisation showed water to be the most efficient extraction solvent followed by $50 \%$ aqueous methanol, methanol, ethanol, hexane, and ethyl acetate. It was observed that the sonication method was the most effective at extracting both analytes. The sonication method also has the advantage of being simpler to use and is amenable to batch processing. A study was carried out to determine the analytes remaining in the herb following extraction by the selected method. The percentage residual chlorogenic and caffeic acids left over was $0.227 \pm 11.5 \%$ RSD and $0.036 \pm$ $30.9 \%$ RSD (5 replicates each). The \%RSD values are high due to the low concentrations of the residual analytes. From these findings it is evident that the selected method is able to recover $\geq 95.0 \%$ of the selected analytes in the raw herb sample. Three types of membrane filters were tested to 
TABLE 2: Recoveries for chlorogenic acid and caffeic acid in the Xu Duan.

\begin{tabular}{|c|c|c|c|c|c|c|}
\hline \multirow{3}{*}{ Compound } & \multicolumn{6}{|c|}{$\%$ recovery $\pm \% \mathrm{RSD}^{\mathrm{a}}$} \\
\hline & \multicolumn{3}{|c|}{ Chlorogenic acid } & \multicolumn{3}{|c|}{ Caffeic acid } \\
\hline & $50 \%$ spike & $100 \%$ spike & $200 \%$ spike & $50 \%$ spike & $100 \%$ spike & $200 \%$ spike \\
\hline Raw herb & $98.76 \pm 2.4$ & $96.31 \pm 2.4$ & $104.56 \pm 3.6$ & $80.52 \pm 9.6$ & $88.26 \pm 3.6$ & $92.85 \pm 6.7$ \\
\hline
\end{tabular}

${ }^{\mathrm{a}}$ Mean recovery $\pm \% \mathrm{RSD}$ calculated from 7 replicate extractions and analyses.

TABLE 3: Comparison of intensities of the qualifier ion(s) for chlorogenic acid $(m / z 85)$ and caffeic acid $(m / z 89,135)$ obtained for the standard and raw herb.

\begin{tabular}{|c|c|c|c|c|}
\hline \multirow{2}{*}{ Analyte } & \multicolumn{2}{|c|}{$m / z$ ion (relative intensity $(\%)^{\mathrm{a}}$ ) } & \multirow{2}{*}{ Relative diff. $(\%)^{\mathrm{b}}$} & \multirow{2}{*}{ Permitted tolerances } \\
\hline & Standard & Raw herb & & \\
\hline Chlorogenic acid & $85(7)$ & $85(6)$ & $14^{\mathrm{c}}$ & $\pm 50 \%$ \\
\hline \multirow{2}{*}{ Caffeic acid } & $89(61)$ & $89(50)$ & $18^{\mathrm{c}}$ & $\pm 20 \%$ \\
\hline & $135(39)$ & $135(33)$ & $15^{\mathrm{c}}$ & $\pm 25 \%$ \\
\hline
\end{tabular}

${ }^{\mathrm{a}}$ Average calculated from 5 replicates.

${ }^{\mathrm{b}}$ Relative difference (absolute difference/relative intensity of standard) $\times 100$.

${ }^{c}$ Maximum permitted tolerance of the European Union guidelines [11].

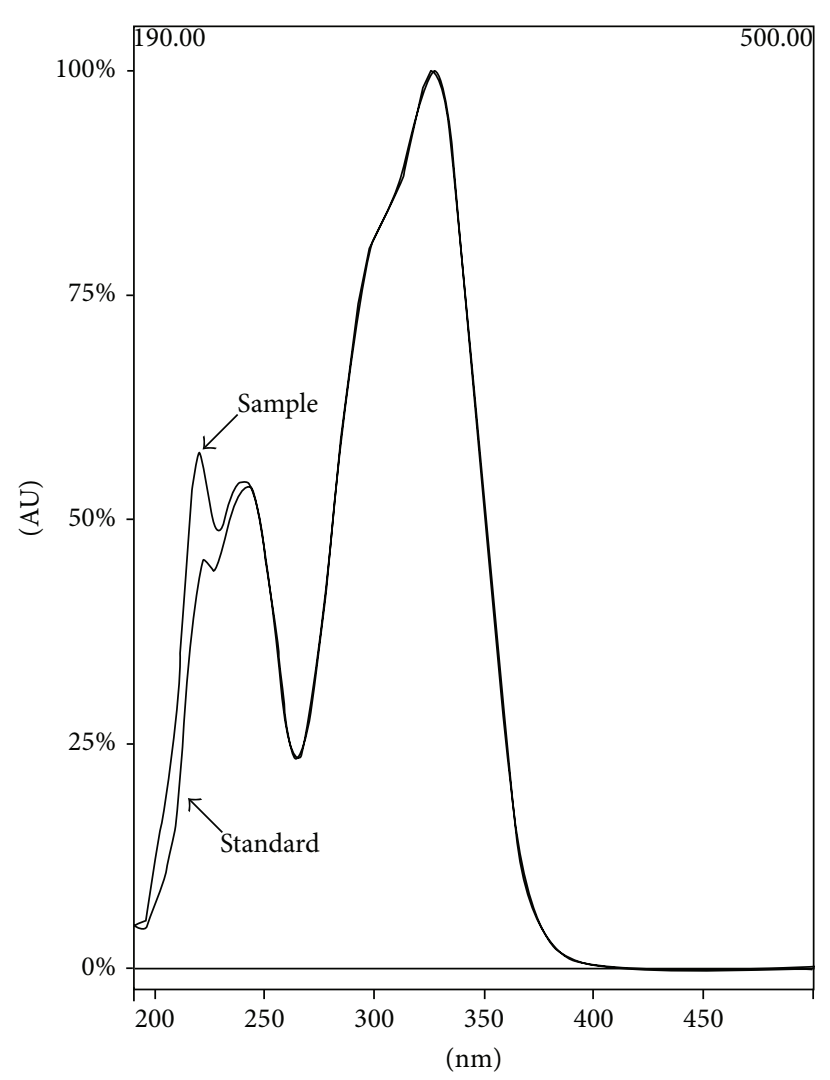

(a)

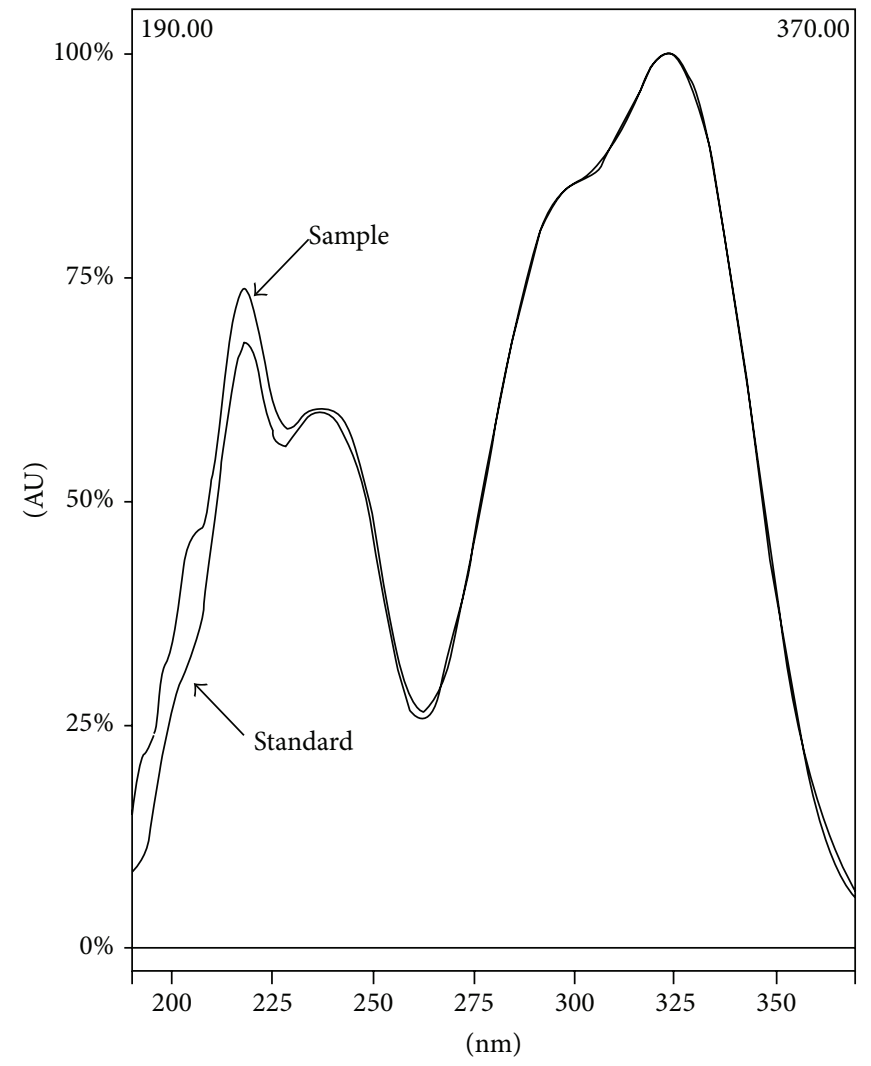

(b)

FIGURE 3: Comparison of UV spectra of the standard and sample peaks for chlorogenic acid (a) and caffeic acid (b) peaks. 
TABLE 4: Concentration of chlorogenic acid and caffeic acid in several Xu Duan raw herbs determined by HPLC-PDA.

\begin{tabular}{lccc}
\hline Sample & \multicolumn{2}{c}{ Mean $(\mathrm{mg} / \mathrm{g}) \pm \% \mathrm{RSD}^{\mathrm{a}}$} & Chlorogenic/caffeic ratio \\
\hline R-I & Chlorogenic acid & Caffeic acid & 7.1 \\
R-II & $4.46 \pm 1.0$ & $0.63 \pm 0.7$ & 6.7 \\
R-III & $2.76 \pm 3.0$ & $0.41 \pm 2.7$ & 16.7 \\
R-IV & $1.66 \pm 1.8$ & $0.10 \pm 4.7$ & 65.1 \\
\hline
\end{tabular}

${ }^{\mathrm{a} C a l c u l a t e d}$ from 5 replicates.

determine the amount of analyte retained by the filter when filtering the prepared raw herb extract. It could be observed that the PVDF filter retained the least percentage of analyte. And had twice the least analyte retention efficiency of the PTFE and nylon filters. Thus PVDF filters were used to filter each sample prior to analysis.

3.3. Method Validation. Sample R-I was used for the validation studies. The concentration of analytes in the unspiked sample analysed by the method was $33.2 \mathrm{mg} / \mathrm{g}$ and $1.8 \mathrm{mg} / \mathrm{g}$ for chlorogenic acid and caffeic acid, respectively. The 50,100, and $200 \%$ spike recovery results for the Xu Duan raw herb are presented in Table 2. For the raw herb the recoveries range from 80.52 to $104.56 \%$ (average $93.54 \%$ ).

For the raw herb, the average recovery across the three spiking levels for chlorogenic acid and caffeic acid is $99.88 \%$ and $87.21 \%$, respectively. The \%RSD for each recovery level varied from 2.4 to $9.6 \%$ (average $4.7 \%$ ). The calibration curves obtained for each analyte showed good linearity with correlations of determination $\left(r^{2}\right)>0.999$ and the linear ranges for chlorogenic and caffeic acids were between 8.7$174.5 \mu \mathrm{g} \mathrm{mL}^{-1}$ and 3.3-65.9 $\mu \mathrm{g} \mathrm{mL}^{-1}$, respectively. The limits of detection (LOD) for chlorogenic and caffeic acids are determined as three times the SD obtained from seven replicate extractions and analyses of the raw herb were 0.13 and $0.02 \mathrm{mg} / \mathrm{g}$, respectively. The limits of quantitation (LOQ) for chlorogenic and caffeic acids are determined as ten times the SD obtained from seven replicate extractions and analyses of the raw herb were 0.43 and $0.05 \mathrm{mg} / \mathrm{g}$, respectively.

3.4. Peak Purity Check and MS Identity Confirmation of Analytes. The UV spectrum of the standard and sample peaks for chlorogenic and caffeic acids match closely as shown in Figure 3. At the quantitation wavelength of $325 \mathrm{~nm}$ there is almost exact overlap.

Identity confirmation is achieved by observing the presence of the correct $\mathrm{m} / \mathrm{z}$ ions and the intensity ratios of those ions obtained for the sample and standard peaks. The daughter ions of chlorogenic acid (precursor $[\mathrm{M}-\mathrm{H}]^{-} \mathrm{m} / \mathrm{z}$ 354, daughter ions $m / z 191$ and 85) and the daughter ions of caffeic acid (precursor $[\mathrm{M}+\mathrm{H}]^{+} \mathrm{m} / z$ 181, daughter ions $\mathrm{m} / \mathrm{z}$ 163, 135 and 89) are summarised in Table 3. The proposed fragmentation patterns are shown in Figures 4 and 5. The differences in intensities for the standard and the sample peaks are within the acceptable tolerances set [11].

MS identity confirmation is thus achieved by observing the presence of the correct mass for the $[\mathrm{M}-\mathrm{H}]^{-}$ion for

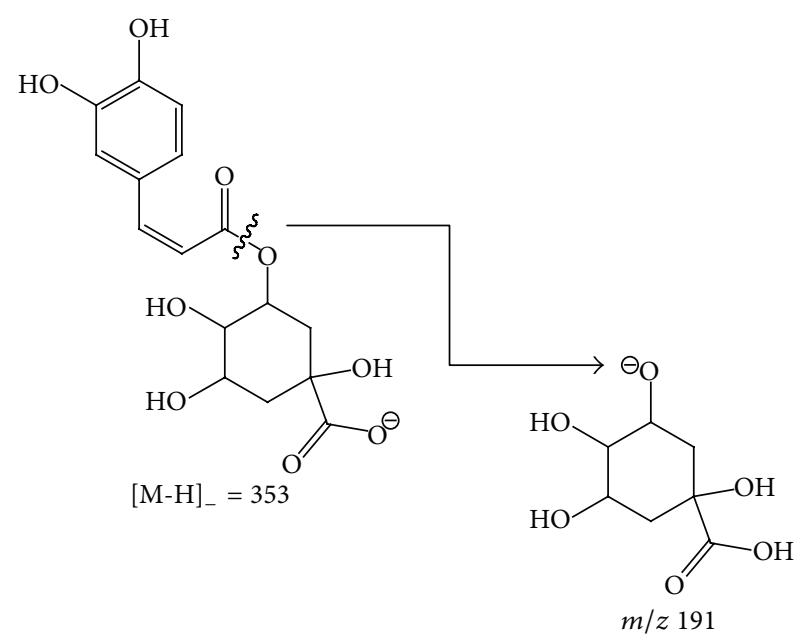

FIGURE 4: Proposed fragmentation pattern for chlorogenic acid showing the formation of the $m / z 191$ daughter ion from the [M$\mathrm{H}]^{-}=353$ precursor ion.

chlorogenic acid and $[\mathrm{M}-\mathrm{H}]^{+}$ion for caffeic acid, the presence of the same $m / z$ daughter ions between sample and standard peaks, and their relative intensity ratios. Furthermore the observed $\mathrm{m} / \mathrm{z}$ fragments can be reasonably explained as shown by the proposed fragmentation pattern for the two acids.

3.5. Comparison of Concentration of Chlorogenic and Caffeic Acids in Xu Duan Raw Herb Obtained from Different Suppliers Determined by HPLC-PDA. The chlorogenic acid and caffeic acid concentrations in the raw herbs are presented in Table 4.

The concentration of chlorogenic acid in the raw herbs varies significantly, with R-I and R-IV having marginally higher levels compared to the other two samples. The caffeic acid concentrations are quite low in all the samples with the sample used for the validation having the highest concentration of caffeic acid. There also does not seem to be a consistent ratio between the concentrations of the two acids. The observed variations could be due to many factors including different growing, harvesting, and storage conditions and the age of the herb.

\section{Conclusion}

A HPLC-PDA method has been developed for the quantitation of chlorogenic and caffeic acids in the Xu Duan raw 


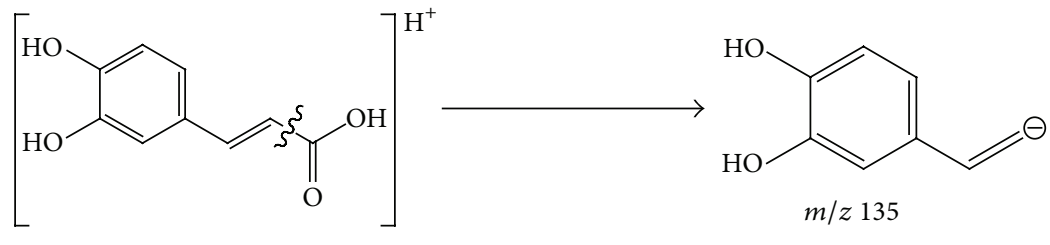

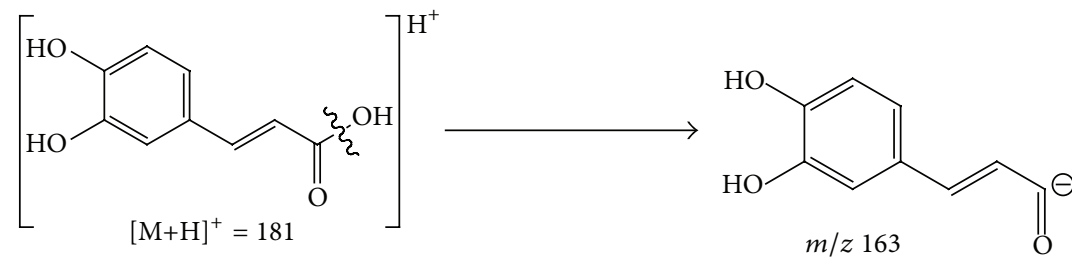<smiles>O=C([O-])/C=C/c1ccc(O)c(O)c1</smiles>

FIGURE 5: Proposed fragmentation pattern for caffeic acid showing the formation of the $m / z 163,135$, and 89 daughter ions from the $[\mathrm{M}+\mathrm{H}]^{+}=$ 181 precursor ion.

herb. The extraction is simple to perform and uses water for extraction. Both peaks show baseline resolution and the chromatographic analysis can be completed in $35 \mathrm{~min}$. Good recoveries and precision of recoveries are obtained. Identity confirmation by ESI-MS/MS is achieved to an acceptable standard.

\section{Conflict of Interests}

The authors declare that there is no conflict of interests regarding the publication of this paper.

\section{Acknowledgment}

This work was supported by the Centre for Complementary Medicine Research (University of Western Sydney).

\section{References}

[1] W. Yan, L. Zhou, and L. Rui, “The study progress in Dipsacus asper wall," Lishizhen Medicine and Materia Medica Research, no. 4, pp. 233-234, 2002.

[2] G. Zhong, Chinese Medicine Study Guide: Materia Medica, People's Medical Publishing House, Beijing, China, 2009.

[3] E. Liu, S. Wu, and G. Fan, "Chemical constituents and pharmacologic actions of the plants from Dipsacus asperoides," Zhonghua Zhongyiyao Xuekan, vol. 28, pp. 1421-1423, 2010.

[4] X. Tian, Y. Wang, H. Liu, S. Yu, and W. Fang, "On the chemical constituents of Dipsacus asper," Chemical and Pharmaceutical Bulletin, vol. 55, no. 12, pp. 1677-1681, 2007.
[5] Y. Jiang, K. Satoh, K. Kusama, S. Watanabe, and H. Sakagami, "Interaction between chlorogenic acid and antioxidants," Anticancer Research, vol. 20, no. 4, pp. 2473-2476, 2000.

[6] U. Jin, J. Lee, S. Kang et al., "A phenolic compound, 5-caffeoylquinic acid (chlorogenic acid), is a new type and strong matrix metalloproteinase-9 inhibitor: isolation and identification from methanol extract of Euonymus alatus," Life Sciences, vol. 77, no. 22, pp. 2760-2769, 2005.

[7] Y. Jiang, K. Satoh, S. Watanabe, K. Kusama, and H. Sakagami, "Inhibition of chlorogenic acid-induced cytotoxicity by COCl2," Anticancer Research, vol. 21, no. 5, pp. 3349-3353, 2001.

[8] B. Ma and S. Liang, "Progress report on extraction and separation of chlorogenic acid from eucomia ulmoides," Shaanxi Forest Science and Technology, vol. 4, pp. 74-79, 2003.

[9] M. R. Olthof, P. C. H. Hollman, and B. M. Katan, "Chlorogenic acid and caffeic acid are absorbed in humans," Journal of Nutrition, vol. 131, no. 1, pp. 66-71, 2001.

[10] X. Zhu, A. Bensoussan, L. Zhu et al., "Primary dysmenorrhoea: a comparative study on Australian and Chinese women," Complementary Therapies in Medicine, vol. 17, no. 3, pp. 155-160, 2009.

[11] European Commission Directorate for Agriculture, "Commission decision of 12 August 2002 implementing Council Directive 96/23/EC concerning the performance of analytical methods and the interpretation of results," Official Journal of the European Communities, vol. 221, pp. 8-36. 

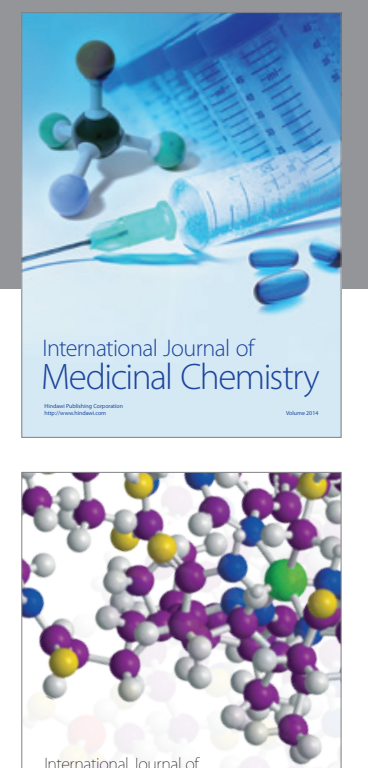

\section{Carbohydrate} Chemistry

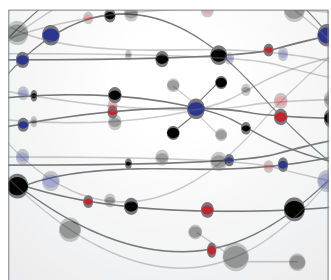

The Scientific World Journal
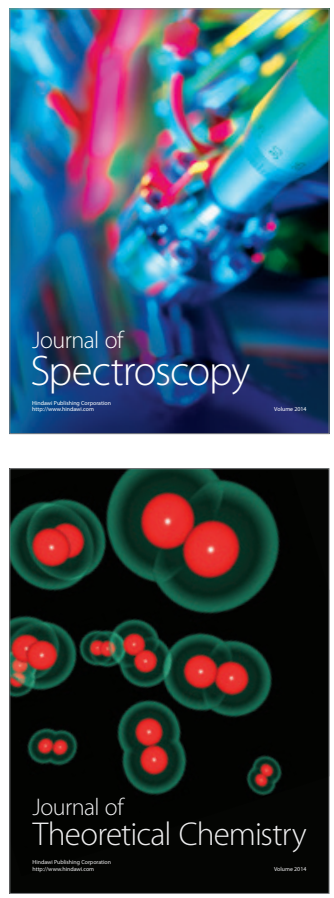
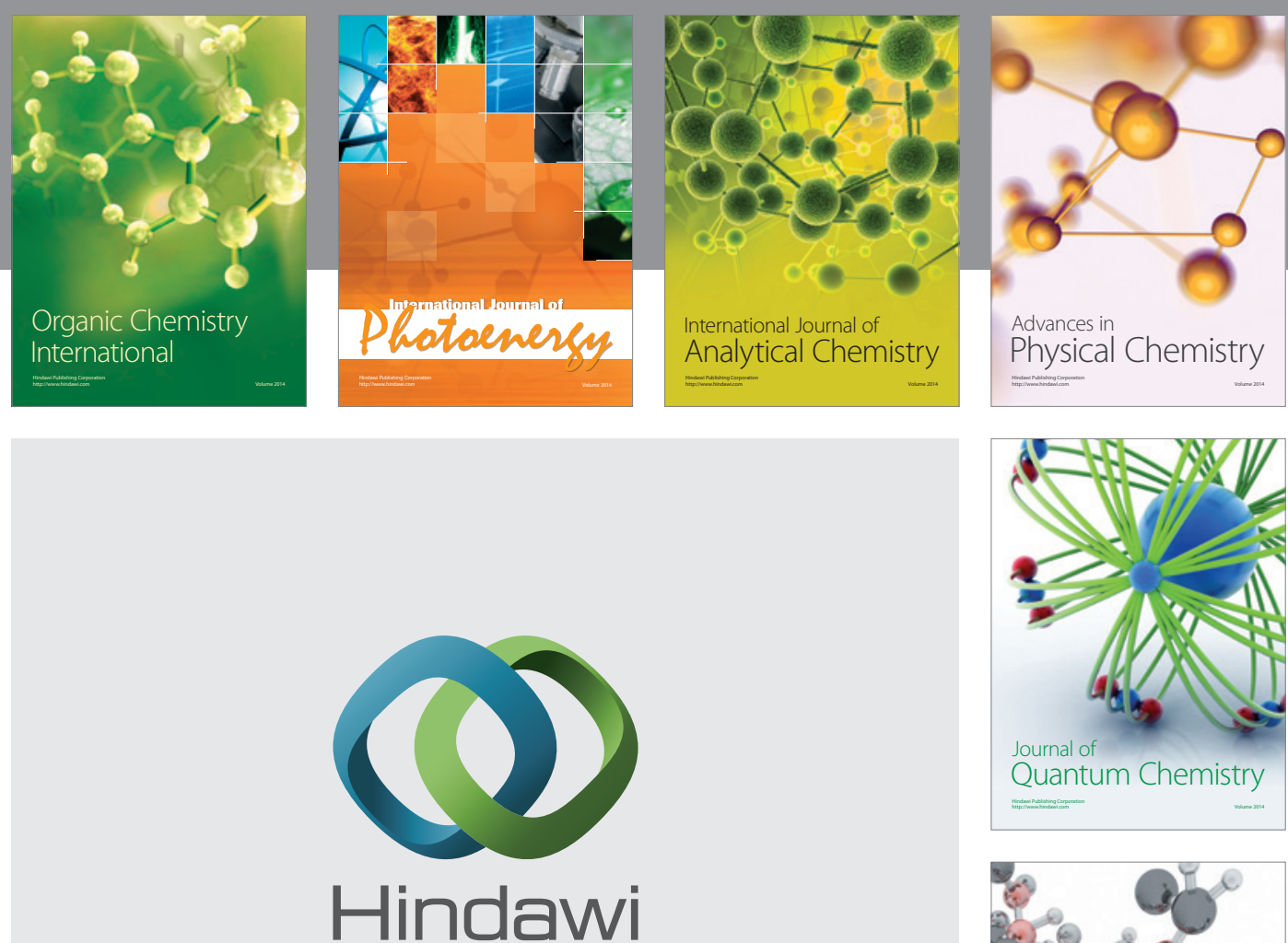

Submit your manuscripts at

http://www.hindawi.com

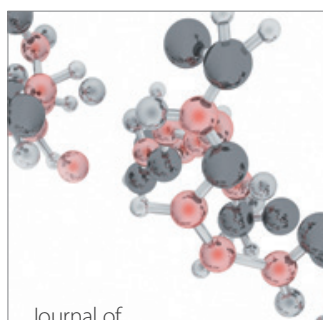

Analytical Methods

in Chemistry

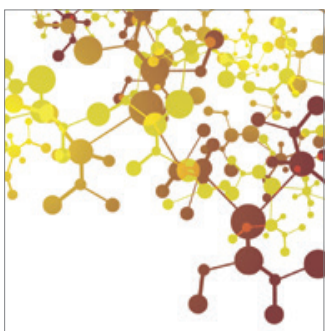

Journal of

Applied Chemistry

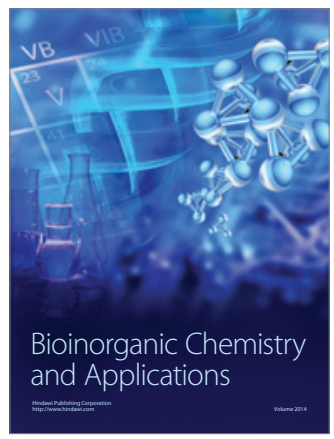

Inorganic Chemistry
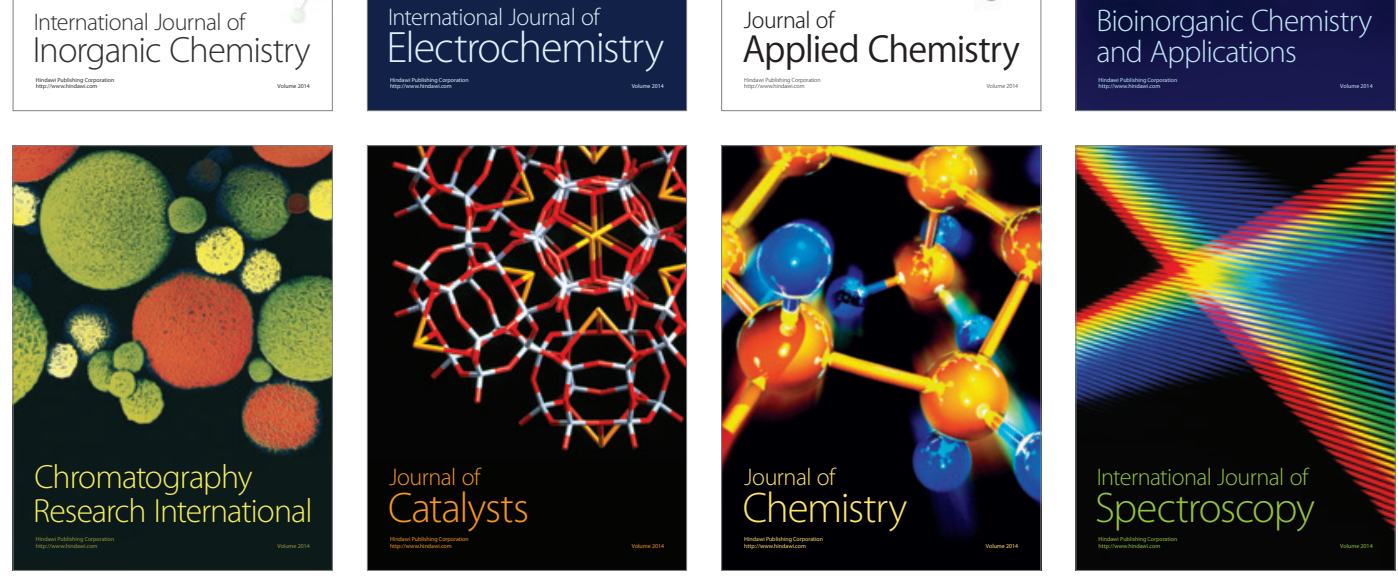